\title{
Problematic Activities of Daily Life are Weakly Associated With Clinical Characteristics in COPD
}

Citation for published version (APA):

Annegarn, J., Meijer, K., Passos, V. L., Stute, K., Wiechert, J., Savelberg, H. H. C. M., Schols, A. M. W. J., Wouters, E. F. M., \& Spruit, M. A. (2012). Problematic Activities of Daily Life are Weakly Associated With Clinical Characteristics in COPD. Journal of the American Medical Directors Association, 13(3), 284-290. https://doi.org/10.1016/j.jamda.2011.01.002

Document status and date:

Published: 01/03/2012

DOI:

10.1016/j.jamda.2011.01.002

Document Version:

Publisher's PDF, also known as Version of record

Document license:

Taverne

Please check the document version of this publication:

- A submitted manuscript is the version of the article upon submission and before peer-review. There can be important differences between the submitted version and the official published version of record.

People interested in the research are advised to contact the author for the final version of the publication, or visit the DOI to the publisher's website.

- The final author version and the galley proof are versions of the publication after peer review.

- The final published version features the final layout of the paper including the volume, issue and page numbers.

Link to publication

\footnotetext{
General rights rights.

- You may freely distribute the URL identifying the publication in the public portal. please follow below link for the End User Agreement:

www.umlib.nl/taverne-license

Take down policy

If you believe that this document breaches copyright please contact us at:

repository@maastrichtuniversity.nl

providing details and we will investigate your claim.
}

Copyright and moral rights for the publications made accessible in the public portal are retained by the authors and/or other copyright owners and it is a condition of accessing publications that users recognise and abide by the legal requirements associated with these

- Users may download and print one copy of any publication from the public portal for the purpose of private study or research.

- You may not further distribute the material or use it for any profit-making activity or commercial gain

If the publication is distributed under the terms of Article $25 \mathrm{fa}$ of the Dutch Copyright Act, indicated by the "Taverne" license above, 
Original Study

\title{
Problematic Activities of Daily Life are Weakly Associated With Clinical Characteristics in COPD
}

\author{
Janneke Annegarn MSc ${ }^{\mathrm{a}, *}$, Kenneth Meijer PhD ${ }^{\mathrm{a}}$, Valeria Lima Passos $\mathrm{PhD}^{\mathrm{b}}$, Katharina Stute $\mathrm{MSc}^{\mathrm{a}}$, \\ Jozé Wiechert BS ${ }^{c}$, Hans H.C.M. Savelberg PhD ${ }^{\mathrm{a}}$, Annemie M.W.J. Schols PhD ${ }^{\mathrm{d}}$, \\ Emiel F.M. Wouters PhD, MD ${ }^{\mathrm{d}, \mathrm{e}}$, Martijn A. Spruit PhD ${ }^{\mathrm{e}}$, on behalf of the Ciro+ Rehabilitation Network \\ ${ }^{a}$ Human Movement Science, NUTRIM School for Nutrition, Toxicology, and Metabolism, Maastricht University Medical Centre, Maastricht, The Netherlands \\ ${ }^{\mathrm{b}}$ Methodology and Statistics, Maastricht University Medical Centre, Maastricht, The Netherlands \\ ${ }^{\mathrm{C}}$ Occupational therapy, CIRO+, a centre of expertise for chronic organ failure, Horn, The Netherlands \\ ${ }^{\mathrm{d}}$ Respiratory Medicine, NUTRIM School for Nutrition, Toxicology and Metabolism Maastricht University Medical Centre, Maastricht, The Netherlands \\ e Program Development Centre, CIRO+, a centre of expertise for chronic organ failure, Horn, The Netherlands
}

Keywords:

Activities of daily living

Canadian Occupational Performance

Measure

chronic obstructive pulmonary disease

performance

satisfaction

\begin{abstract}
A B S T R A C T
Background: Problematic activities of daily life (ADLs) can be the main reason to refer patients with chronic obstructive pulmonary disease (COPD) for pulmonary rehabilitation. To date, information on problematic ADLs and their clinical correlates in COPD remain scarce. This retrospective chart review aimed to identify the most prevalent self-reported problematic ADLs in COPD patients, determine performance and satisfaction scores of these problematic ADLs, and explore the association between 13 clinical determinants and 4 problematic ADL domains.

Methods: A total of 820 COPD patients entering pulmonary rehabilitation assessment were included in this retrospective study. Self-reported problematic ADLs were assessed using the Canadian Occupational Performance Measure, administered by occupational therapists in the form of a semistructured interview.

Results: COPD patients (59\% male, age $63.6 \pm 9.3$ years, $\mathrm{FEV}_{1}$ (\%pred): $46.4 \pm 18.4$ ) reported 2999 problematic ADLs. The most prevalent problematic ADLs were walking (68\%), stair climbing (35\%), and cycling (30\%). Moreover, 30\% of the patients reported "not able to do any of the scored problematic ADL" and $44 \%$ were "not satisfied at all with the performance of any of the scored problematic ADL." Significant but weak associations were found between clinical determinants (eg, physical and psychosocial) and problematic ADLs.

Conclusions: The lack of a strong association between problematic ADLs and clinical determinants emphasizes the need for individualized assessment of these ADLs to allow tailored intervention.
\end{abstract}

Published by Elsevier Inc. on behalf of the American Medical Directors Association, Inc.
Self-reported function meaningfully reflects physiology in moderately to severely disabled older adults. ${ }^{1}$ Patients with chronic obstructive pulmonary disease (COPD) experience a progressive reduction in the ability to perform activities of daily living (ADLs)

The CIRO+ Rehabilitation Network consists of CIRO+, Horn (NL), St. Laurentius Hospital, Roermond (NL), St. Jans gasthuis, Weert (NL), St Anna Hospital, Geldrop (NL), Elkerliek Hospital, Helmond (NL), Maxima Medical Centre, Veldhoven (NL), and Maastricht University Medical Centre, Maastricht (NL).

The authors report no conflicts of interest.

* Address correspondence to Janneke Annegarn, Human Movement Science, NUTRIM School for Nutrition, Toxicology and Metabolism, Maastricht University Medical Centre, Universiteitssingel 50, 6229 ER, PO Box 616, 6200 MD, Maastricht, Netherlands.

E-mail address: Janneke.annegarn@maastrichtuniversity.nl (J. Annegarn). during the course of their disease. ${ }^{2}$ Patients who are dissatisfied with the ability to perform ADLs are often the ones referred to pulmonary rehabilitation. $^{2}$

Patients' self-perceived performance and satisfaction of problematic ADLs can be measured using patient-reported questionnaires. Patient-reported questionnaires show good validity for measuring general problematic ADLs, but poorly identify patients' individual needs. ${ }^{3}$ An alternative approach is offered by interviews. Although these can be time consuming, they enable an exploration of the individual problematic ADLs. ${ }^{4,5}$ The Canadian Occupational Performance Measure (COPM) is such an individualized outcome measure, ${ }^{6}$ which can be used reliably in patients with activity limitations and participation restrictions (eg, COPD, chronic pain, hand injury, multiple sclerosis, diabetes mellitus). ${ }^{7,8}$ Indeed the COPM has been recommended for use during the 
assessment of pulmonary rehabilitation programs for patients with COPD. ${ }^{9,10}$ However, an overview of the distribution of problematic ADLs in a large cohort of COPD patients is currently lacking.

The World Health Organization has developed the framework International Classification of Functioning, Disability and Health to describe and analyze the functional consequences of various health conditions. ${ }^{11}$ International Classification of Functioning, Disability and Health does not take into account that the importance and satisfaction attributed to the ability to perform various ADLs may vary among patients. There is limited information on whether and to what extent objective clinical determinants are associated with the subjective functional consequences of COPD. For example, it has been reported that female COPD patients perceive more loss of functional performance within "home management" compared with male COPD patients. ${ }^{12}$ Moreover, given previous reports, it seems reasonable to hypothesize that also living alone, ${ }^{13,14}$ being younger, ${ }^{15,16}$ having a higher degree of airflow limitation, ${ }^{16}$ receiving long-term oxygen therapy, ${ }^{5,17}$ having a poor functional exercise performance (lower 6-minute walking distance), ${ }^{12,18}$ not using a walking aid (eg, rollator or cane), ${ }^{19}$ depletion of fat-free mass, ${ }^{20}$ increased fat mass, ${ }^{21}$ and lower scores on variables reflecting dyspnea, ${ }^{18,22}$ psychological status, ${ }^{14,18}$ and/or health status ${ }^{18,23}$ may decrease performance and satisfaction of problematic ADLs in COPD. Unfortunately, available studies are limited by sample size and/or focused on prespecified ADLs. Nevertheless, the identification of clinical determinants of problematic ADLs may allow clinicians to better monitor and restore the impaired functional performance and/or satisfaction in patients with COPD.

Therefore, the aim of the current study was threefold: (1) to identify the most prevalent problematic ADLs in patients with COPD, (2) to determine performance and satisfaction scores for these ADLs, and (3) to explore the association between clinical determinants and problematic ADLs.

\section{Methods}

\section{Participants}

Data were extracted from the records of 1102 clinically stable patients with the diagnosis of "COPD" who were evaluated at CIRO+, a center of excellence for chronic organ failure in Horn (the Netherlands), for rehabilitation eligibility between January 1, 2005, and April 1, 2009. Of these records, 820 met the following inclusion criteria: all necessary data present, a forced expiratory $\left(\mathrm{FEV}_{1}\right)$ / forced vital capacity (FVC) ratio of 0.7 or less, and not representing a repeat admission for the same patient. These retrospective analyses are institutional review board exempt because of the use of deidentified, preexisting data.

\section{Measures}

As part of routine assessment for rehabilitation eligibility, patients underwent a 6 -minute walking test in accordance with the guidelines of the American Thoracic Society, ${ }^{24}$ including a practice walk. The best 6-minute walk distance was expressed as a percentage of the predicted values. ${ }^{25}$ Patients also underwent routine postbronchodilator spirometry, physical examination, and medical history assessment. ${ }^{26}$ Length and weight were assessed to obtain the body mass index (body weight in $\mathrm{kg} / \mathrm{m}^{2}$ ), and a bioelectrical impedance analysis was used (Bodystat 1500, Euromedix, Leuven) to determine the fat-free mass index and the fat mass index using disease-specific equations. ${ }^{27}$ Patients were identified as current smokers when arterial HbCO was $2 \%$ or higher.
All patients completed the Medical Research Council (MRC) dyspnea scale, the St. George's Respiratory Questionnaire (SGRQ), and the Hospital Anxiety and Depression Scale. ${ }^{28}$ Moreover, patients underwent an intake by an occupational therapist, including the COPM. $^{7}$

The COPM is administered in the form of a semistructured interview, in which the patient is encouraged to identify and discuss specific problematic ADLs. Previous to quantitative analyses, ${ }^{29,30}$ problematic ADLs were simplified and categorized into 4 COPM domains: "self-care," "productivity," "leisure," and "mobility." 6 Mobility-related problematic ADLs are usually part of the COPM domain "self-care." ${ }^{31}$ However, in COPD patients, mobility-related problematic ADLs were expected to be highly prevalent $^{12}$ and therefore analyzed separately. Next, patients identified their perception of how well they were performing the problematic ADL (performance score) and how satisfied they were with this level of performance (satisfaction score). These scores were ascertained by using the cue cards to identify a score between 1 ("not able to do it" or "not at all satisfied," respectively) to 10 points ("able to do it extremely well" or "extremely satisfied").

\section{Statistics}

Mean and SD are displayed for quantitative variables with symmetric distributions and percentages for categorical variables. A limited number of patients with Global Initiative for Chronic Obstructive Lung Disease (GOLD) stage $1(\mathrm{n}=48)$ and MRC dyspnea grade $1(n=20)$ were evaluated at CIRO+. Therefore, GOLD stages 1 and 2 were combined for the analyses. The same was done for MRC dyspnea grades 1 and 2 . The comparisons were conducted with 1way analysis of variance or chi-square tests as appropriate. Adjustment for multiple testing was conducted via False Discovery Rate. Results were considered statistically significant when False Discovery Rate $P$ value was less than .05 . The 10 most prevalent problematic ADLs were described for the whole group and after stratification for sex, age ( $<65$ or $\geq 65$ years), and GOLD stage. Age was dichotomized according to the mean age as reported in the Cochrane review of Lacasse and colleagues. ${ }^{32}$

Logistic regression analyses were conducted to test whether reporting (yes/no) any of the 4 identified problematic COPM domains ("self-care", "productivity", "leisure", and "mobility") was associated with the following clinical determinants previously reported to affect ADLs in COPD patients: age (years), sex, living status (alone/together), $\mathrm{FEV}_{1}$ (\% predicted), fat-free mass index (kg/ $\mathrm{m}^{2}$ ), fat mass index $\left(\mathrm{kg} / \mathrm{m}^{2}\right), 6$-minute walk distance (\% predicted), walking aid use (yes/no), receiving long-term oxygen therapy (yes/ no), MRC dyspnea grade, SGRQtotal score, and anxiety score and depression score (both Hospital Anxiety and Depression Scales). Logistic models were fitted for each of the 4 COPM domains separately. The area under the curve (AUC) of the receiver operating characteristic (ROC) curve was calculated as a measure of the final models' predictive values. This same set of predictors was tested in their association with performance and satisfaction scores via multiple ordinary least squares (OLS) regression models. Performance and satisfaction scores were averaged over repeated measures per patient within each COPM domain separately. These mean scores were used as outcome variables in the OLS regression models. For both OLS and logistic regression analyses, multicollinearity tests were carried out in advance and the variables were retained in the models, if the variance inflation factor was smaller than 3.0. A top-down procedure was handled for the selection of the final model variables. For all tests, a statistical significance level of $5 \%$ or less was handled. Data analyses were performed with Statistical Package for Social Sciences (SPSS) 15.0 for Windows (SPSS Inc., Chicago, IL). 
Table 1

Patients' Characteristics

\begin{tabular}{|c|c|c|c|c|c|}
\hline & Total $(\mathrm{N}=820)$ & GOLD $1 / 2(n=289)$ & GOLD $3(n=234)$ & GOLD $4(n=297)$ & FDR $P$ Value \\
\hline Sex, \% male & 59.0 & 51.2 & $65.4^{*}$ & $61.6^{*}$ & .0034 \\
\hline Age, y & $63.6 \pm 9.3$ & $63.8 \pm 9.5$ & $63.0 \pm 9.5$ & $63.8 \pm 9.0$ & .5710 \\
\hline $\mathrm{FEV}_{1}, \mathrm{~L}$ & $1.3 \pm 0.6$ & $1.75 \pm 0.53$ & $1.1 \pm 0.3^{*}$ & $0.86 \pm 0.3^{*, \dagger}$ & $<.0001$ \\
\hline $\mathrm{FEV}_{1}, \%$ pred & $46.4 \pm 18.4$ & $65.9 \pm 12.5$ & $40.1 \pm 5.7^{*}$ & $32.3 \pm 12.4^{*, \dagger}$ & $<.0001$ \\
\hline Tiffeneau index, \% & $39.6 \pm 11.7$ & $49.2 \pm 9.4$ & $36.9 \pm 7.8^{*}$ & $32.4 \pm 10.0^{*, \dagger}$ & $<.0001$ \\
\hline $\mathrm{pO}_{2}, \mathrm{kPa}$ & $9.4 \pm 1.5$ & $9.8 \pm 1.4$ & $9.6 \pm 1.1$ & $8.8 \pm 1.8^{*, \dagger}$ & $<.0001$ \\
\hline $\mathrm{pCO}_{2}, \mathrm{kPa}$ & $5.4 \pm 0.9$ & $5.0 \pm 0.6$ & $5.2 \pm 0.5^{*}$ & $5.9 \pm 1.2^{*, \dagger}$ & $<.0001$ \\
\hline Current smoker, \% & 41.8 & 43.6 & 43.6 & 38.7 & .4148 \\
\hline LTOT, \% & 21.7 & 0.0 & 0.0 & $59.9^{*, \dagger}$ & $<.0001$ \\
\hline Charlson score, points & $1.7 \pm 1.2$ & $1.6 \pm 1.0$ & $1.7 \pm 1.1$ & $1.8 \pm 1.4^{*}$ & .0700 \\
\hline MRC dyspnea grade & $3.4 \pm 1.1$ & $2.9 \pm 1.1$ & $3.4 \pm 1.1^{*}$ & $4.0 \pm 1.04^{*, \dagger}$ & $<.0001$ \\
\hline BMI, $\mathrm{kg} / \mathrm{m}^{2}$ & $25.2 \pm 5.0$ & $25.9 \pm 4.7$ & $24.7 \pm 4.8^{*}$ & $25.0 \pm 5.3^{*}$ & .0115 \\
\hline FFMI, $\mathrm{kg} / \mathrm{m}^{2}$ & $16.3 \pm 2.2$ & $16.5 \pm 2.1$ & $16.3 \pm 2.1$ & $16.2 \pm 2.3$ & .1956 \\
\hline FMI, $\mathrm{kg} / \mathrm{m}^{2}$ & $8.9 \pm 3.4$ & $9.4 \pm 3.2$ & $8.4 \pm 3.4^{*}$ & $8.8 \pm 3.6^{*}$ & .0032 \\
\hline Living alone, $\%$ & 23.9 & 22.8 & 21.4 & 26.9 & .3119 \\
\hline 6MWD, m & $431.7 \pm 125.3$ & $487.3 \pm 105.0$ & $451.9 \pm 113.7^{*}$ & $361.7 \pm 119.4^{*, \dagger}$ & $<.0001$ \\
\hline 6MWD, \%pred & $79.8 \pm 21.9$ & $91.9 \pm 17.5$ & $81.4 \pm 18.0^{*}$ & $66.9 \pm 21.5^{*, \dagger}$ & $<.0001$ \\
\hline Walking aid, \% & 29.3 & 9.3 & 12.4 & $62.0^{*, \dagger}$ & $<.0001$ \\
\hline SGRQ Impact, points & $43.8 \pm 18.6$ & $38.3 \pm 17.9$ & $43.4 \pm 17.9^{*}$ & $49.5 \pm 18.2^{*, \dagger}$ & $<.0001$ \\
\hline SGRQ $_{\text {Activity }}$, points & $72.1 \pm 18.7$ & $65.1 \pm 19.4$ & $70.0 \pm 17.9^{*}$ & $80.4 \pm 14.9^{*, \dagger}$ & $<.0001$ \\
\hline SGRQ $_{\text {symptom, }}$ points & $60.1 \pm 20.5$ & $56.2 \pm 21.6$ & $61.1 \pm 20.2^{*}$ & $63.2 \pm 19.1^{*}$ & .0003 \\
\hline$S_{G R Q_{\text {total }}, \text { points }}$ & $55.1 \pm 16.2$ & $49.4 \pm 16.2$ & $54.4 \pm 15.6^{*}$ & $61.1 \pm 14.4^{*, \dagger}$ & $<.0001$ \\
\hline Anxiety score, points & $7.6 \pm 4.4$ & $7.2 \pm 3.9$ & $7.4 \pm 4.4$ & $8.0 \pm 4.8^{*}$ & .0579 \\
\hline Depression score, points & $6.9 \pm 4.0$ & $6.4 \pm 3.8$ & $6.7 \pm 3.8$ & $7.6 \pm 4.2^{*, \dagger}$ & .0006 \\
\hline
\end{tabular}

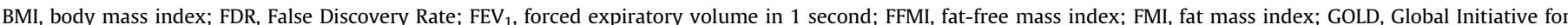
Chronic Obstructive Lung Disease; LTOT, long-term oxygen therapy; SGRQ St. George's Respiratory Questionnaire; 6MWD, 6-minute walk distance.

*Different from GOLD $1+2$.

${ }^{\dagger}$ Different from GOLD 3.

\section{Results}

\section{Patients' Characteristics}

The current cohort consisted mostly of elderly male COPD patients, with generally a normal body composition, and a poor functional exercise performance. About one-third of the patients used a walking aid. As expected, patients in GOLD stage 4 had the worst mean 6-minute walking distance, also after correction for confounding variables, like height, body weight, age, and sex. ${ }^{25}$ Furthermore, mean SGRQ total scores were significantly higher (= worse) among GOLD 4 patients (Table 1 ).

\section{Problematic ADLs}

A total of 820 patients reported 2999 problematic ADLs; 743 patients scored 2 or more problematic ADLs. The COPM domain "mobility" was most frequently scored (86\%) (performance score: $4.2 \pm 1.7$ points, satisfaction score: $3.5 \pm 2.0$ points) followed by "productivity" (56\%) (performance score: $4.3 \pm 1.8$ points, satisfaction score: $3.7 \pm 2.0$ points), "self-care" (55\%) (performance score: $4.8 \pm 1.6$ points, satisfaction score: $4.2 \pm 2.1$ points), and "leisure" (46\%) (performance score: $3.9 \pm 2.0$ points, satisfaction score: $3.3 \pm 2.2$ points).

\section{Top-10 Problematic ADLs}

The 3 most prevalent problematic ADLs were walking, stair climbing and cycling (Table 2). Walking remained the most prevalent problematic ADL after stratification for sex, age ( $<65$ versus $\geq 65$ years) and/or GOLD stage (shown in e-Table 1 , e-Table 2 , and eTable 3 available at www.jamda.com).

A higher proportion of GOLD stage 4 patients scored problematic ADLs within the COPM domain "self-care" compared with GOLD stages $1 / 2$ and $3(P<.001)$. In contrast, the proportion of GOLD stage 4 patients with problematic ADLs within the COPM domain "productivity" was significantly lower $(P=.037$; Figure $1 \mathrm{~A})$. No significant differences were found for the COPM domains "leisure" $(P=.485)$ and "mobility" $(P=.060)$.

Eighty percent of the patients with MRC grade 5 scored 1 or more problematic ADLs on the COPM domain "self-care," although this was significantly lower in the patients with MRC grade 1 or 2 (26\%; $P<.001)$. Moreover, the proportion of patients with 1 or more problematic ADLs within the COPM domain "mobility" was lowest in patients with MRC grade 1 or 2 , but was still highly prevalent $(77 \%)(P=.001$; Figure 1B). The COPM domains "productivity" $(P=$ .389) and "leisure" $(P=.741)$ were not different among MRC dyspnea grades.

\section{Performance and Satisfaction Scores}

The frequency distributions of performance and satisfaction points for each COPM domain after stratification for GOLD are summarized in Figure 2. The proportion of patients scoring 1 point for performance or satisfaction was $6.5 \%$ and $22.5 \%$ for the COPM domain "self-care," respectively; $14.1 \%$ and $27.9 \%$ for "productivity"; $27.1 \%$ and $39.1 \%$ for "leisure"; and $17.7 \%$ and $33.6 \%$ for "mobility."

Table 2

Top 10 Problematic ADLs for All Patients

\begin{tabular}{rllll}
\hline & All Patients $(\mathrm{N}=820)$ & & \\
\cline { 2 - 5 } & Activity & $\%$ & $\mathrm{P}$ & $\mathrm{S}$ \\
\hline 1 & Walking & 68.3 & 4.25 & 3.60 \\
2 & Stair climbing & 35.0 & 4.28 & 3.47 \\
3 & Cycling & 30.0 & 3.83 & 3.42 \\
4 & Showering & 20.1 & 4.90 & 4.25 \\
5 & Gardening & 17.6 & 4.16 & 3.73 \\
6 & Cleaning the floor & 12.2 & 4.62 & 4.05 \\
7 & Dress and undress & 11.0 & 4.94 & 4.39 \\
8 & Sports & 8.9 & 3.03 & 3.08 \\
9 & Social activities & 7.8 & 3.66 & 2.94 \\
10 & Activities with (grand) children & 7.4 & 4.05 & 3.30 \\
\hline
\end{tabular}

$\mathrm{P}$, mean performance score (points); S, mean satisfaction score (points). 

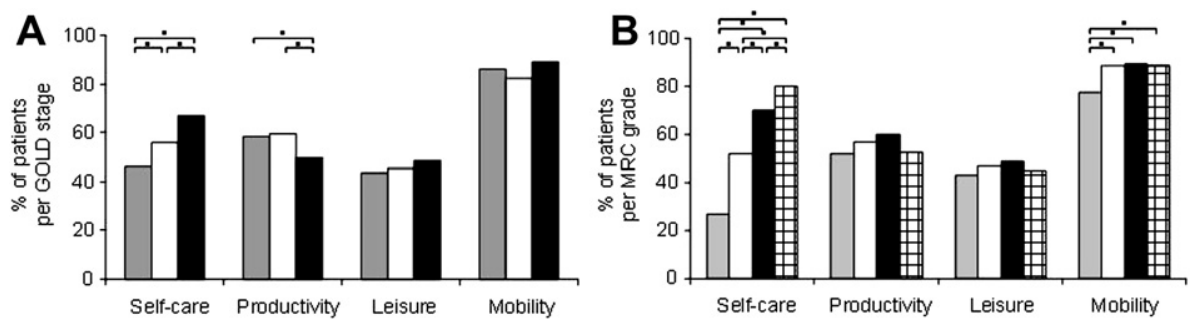

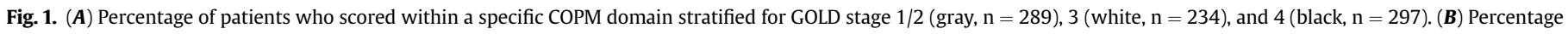

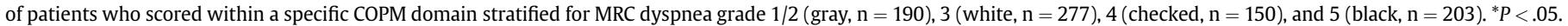

\section{Logistic Regression Analyses}

Several clinical determinants were observed to significantly affect the odds of reporting problematic ADLs in any of the COPM domains. However, no uniform pattern of association was found across the COPM domains. The identified predictors were poor to moderate in discriminating between COPD patients with and without 1 or more problematic ADLs in the 4 COPD domains (ROC Auc: 0.571-0.754, Table 3).

Patients with a lower 6-minute walk distance, a higher MRC dyspnea grade, or a higher total score on the SGRQ had higher odds to score 1 or more problematic ADLs within the COPM domain "self-care." Patients who were younger, who were women, with a higher $\mathrm{FEV}_{1}$ or a higher total score on the SGRQ had higher odds to score 1 or more problematic ADLs within the COPM domain "productivity." Patients who were men or scored higher on depression had higher odds of scoring 1 or more problematic ADLs within the COPM domain "leisure." Patients with a higher MRC dyspnea grade had higher odds of scoring 1 or more problematic ADLs within the COPM domain "mobility" (Table 3).

\section{OLS Regression Analyses}

The results of the OLS regression models used to test for associations between clinical outcomes and the mean scores for performance and satisfaction for each COPM domain are summarized in Table 4. Similar to the logistic analysis, the OLS analysis revealed that performance and satisfaction scores among different COPM domains are complex and cannot be predicted from the same set of predictors. No major predictor was found to influence all domain scores simultaneously. Despite significant associations, the models' goodness of fit was poor ( $R^{2} 7.5$ to 14.6$)$.

\section{Discussion}

This is the most comprehensive evaluation of problematic ADLs in COPD patients to date, in which a staggering range of 2999 problematic ADLs were reported. Walking was the most prevalent problematic ADL independent of age, sex, or GOLD stage. Moreover, a huge proportion of patients were not satisfied at all with 1 or more problematic ADLs. Known clinical determinants of ADLs in
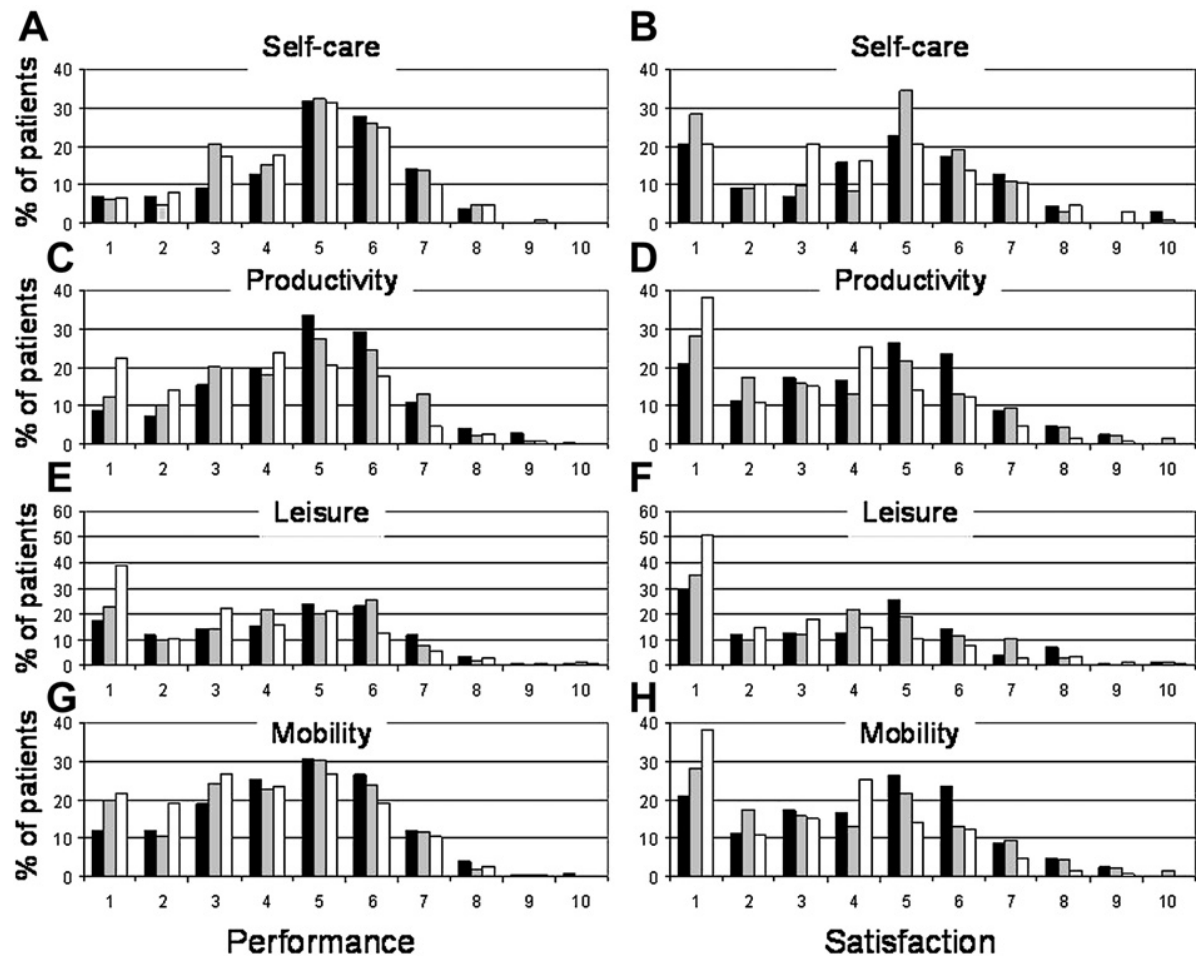

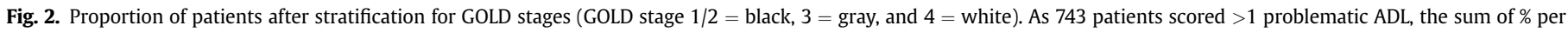

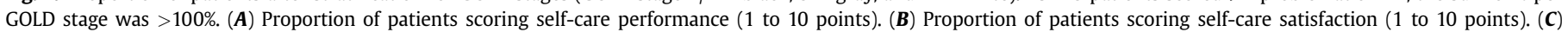

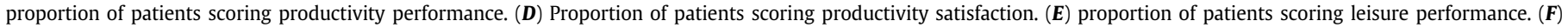
Proportion of patients scoring leisure satisfaction. $(\boldsymbol{G})$ Proportion of patients scoring mobility performance. (H) Proportion of patients scoring mobility satisfaction. 
Table 3

Odds Ratios (OR) of the Model Variables Influencing Reporting (Yes, No) Any of the 4 Canadian Occupational Performance Measure Domains-Logistic Regression

\begin{tabular}{|c|c|c|c|c|c|c|c|c|}
\hline & \multicolumn{2}{|c|}{ Self-care } & \multicolumn{2}{|c|}{ Productivity } & \multicolumn{2}{|c|}{ Leisure } & \multicolumn{2}{|c|}{ Mobility } \\
\hline & OR & Sig. & OR & Sig. & OR & Sig. & OR & Sig. \\
\hline Age & & & 0.975 & & & & & \\
\hline (years) & & & & .000 & & & & \\
\hline 95\% CI: L & & & 0.941 & & & & & \\
\hline $\mathrm{U}$ & & & 0.973 & & & & & \\
\hline Sex & & & 1.586 & & 0.646 & & & \\
\hline$($ Men $=$ ref $)$ & & & & .003 & & .003 & & \\
\hline 95\% CI: L & & & 1.174 & & 0.486 & & & \\
\hline $\mathrm{U}$ & & & 2.142 & & 0.858 & & & \\
\hline 6MWD & 0.990 & & & & & & & \\
\hline (\%pred) & & .028 & & & & & & \\
\hline 95\% CI: L & 0.981 & & & & & & & \\
\hline $\mathrm{U}$ & 0.999 & & & & & & & \\
\hline $\mathrm{FEV}_{1}$ & & & 1.013 & & & & & \\
\hline (\%pred) & & & & .003 & & & & \\
\hline 95\% CI: L & & & 1.004 & & & & & \\
\hline $\mathrm{U}$ & & & 1.021 & & & & & \\
\hline MRC & 1.603 & & & & & & 1.308 & \\
\hline (grade) & & .000 & & & & & & .003 \\
\hline 95\% CI: L & 1.340 & & & & & & 1.096 & \\
\hline $\mathrm{U}$ & 1.918 & & & & & & 1.562 & \\
\hline SGRQ $_{\text {total }}$ & 1.028 & & 1.011 & & & & & \\
\hline (points) & & .000 & & .021 & & & & \\
\hline 95\% CI: L & 1.016 & & 1.002 & & & & & \\
\hline $\mathrm{U}$ & 1.041 & & 1.020 & & & & & \\
\hline Depression & & & & & 1.037 & & & \\
\hline (points) & & & & & & .040 & & \\
\hline 95\% CI: L & & & & & 1.002 & & & \\
\hline $\mathrm{U}$ & & & & & 1.074 & & & \\
\hline Model AUC & 0.754 & & 0.652 & & 0.571 & & 0.587 & \\
\hline 95\% CI: L & 0.721 & & 0.641 & & 0.532 & & 0.528 & \\
\hline $\mathrm{U}$ & 0.788 & & 0.689 & & 0.610 & & 0.646 & \\
\hline
\end{tabular}

ORs are presented per unit increase of the independent variable. Effects of the following variables were also tested, but no statistical significance was detected: Living status, FFMI, FMI, anxiety score, receiving LTOT and using a walking aid. AUC, area under the curve; $\mathrm{CI}$, confidence interval; $\mathrm{FEV}_{1}$, forced expiratory volume in 1 second; FFMI, fat-free mass index; FMI, fat mass index; L, lower; LTOT, longterm oxygen therapy; ref, reference value; SGRQ St. George's Respiratory Questionnaire; Sig., significance; U, upper; 6MWD, 6-minute walk distance.

COPD patients were only weakly associated with performance and satisfaction scores of problematic ADLs in the current analyses. Taken together, the wide range of problematic ADLs and the absence of strong association with clinical determinants emphasize the need for using interview-based performance measures for identification of ADLs that an individual perceives as problematic to perform to allow tailored interventions.

The strength of this study lies in the inclusion of a large sample of COPD patients with different levels of disease severity. The individual problematic ADLs were assessed using a semistructured interview measure, which is beneficial over standardized questionnaires as it does not focus on specific ADLs that may not be most important to the patient. Moreover, this study analyzed 13 clinical determinants previously reported to affect ADLs in COPD patients.

\section{Problematic ADLs}

Walking is most frequently reported to be problematic in daily life, which is in general agreement with small-sized studies that have described the importance of daily walking for COPD patients. ${ }^{4,5,33}$ In addition, 6 of the current top 10 problematic ADLs correspond with previous findings. ${ }^{34}$ All 4 COPM domains are represented in the top 10 of problematic activities, showing the diversity of the problematic ADLs that appear in COPD patients.

\section{Clinical Correlates of Problematic ADLs}

Identifying clinical determinants of problematic ADLs may allow clinicians to better monitor and restore the impaired functional performance and/or satisfaction in patients with COPD. In the present study, the degree of airflow was not associated with performance or satisfaction scores at all. This study is in alignment with previous findings showing that also patients with moderate COPD have significant impairment in ADLs. ${ }^{22}$ Even though MRC dyspnea grade appeared to be somewhat more associated with problematic ADLs, both GOLD classification and MRC dyspnea grade are not discriminative enough to be used as clinical tools for evaluating problematic ADLs of the individual patient.

Better functional exercise performance, lower MRC dyspnea

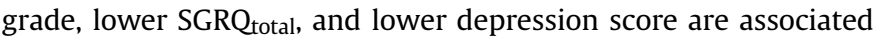
with higher average performance and satisfaction scores in 2 or more COPM domains. In line with this, the same clinical values were previously also found to be associated with the London Chest ADL scale. ${ }^{18}$ Additionally, Katz et $\mathrm{al}^{14}$ found a positive association between the level of psychological distress and difficulty with ADLs.

Women have fewer problematic ADLs within the COPM domain "leisure," whereas the opposite applies for the COPM domain "productivity." This corresponds to previous results on sex differences. ${ }^{12}$ Age was negatively associated with scoring 1 or more problematic ADLs within the COPM domain "productivity," which is probably a result of older patients being more frequently retired.

Although several clinical determinants were shown to significantly affect the odds of reporting any of the 4 COPM domains, the models' predictive power was limited. Likewise, weak correlations were observed between clinical determinants and their identified perception of how well they are performing the problematic ADLs and how satisfied they are with this level of performance. Therefore, it may be speculated that some other factors not included in our models could improve their discriminative power (eg, personal assistance $^{5}$ and self-esteem ${ }^{33}$ ). Most likely, the COPM provides additional clinical relevant information that cannot be predicted from other clinical determinants. Either way, it highlights the importance of assessing the problematic ADLs of individual patients.

\section{Methodological Considerations}

This retrospective chart review focused on clinically stable COPD patients entering pulmonary rehabilitation, which might limit the external validity of the present findings. Statistical analyses were conducted only for patients with complete data $(n=820)$, as missing values were assumed to be at random. In this study, a total of 2999 problematic ADLs were reported. Similar problematic ADLs were reported by the patients in many different ways. In the process of summarizing the overall picture by stipulating major general categories, we noticed some difficulties. For example, some patients reported their ADLs very specifically (eg, problems with showering, taking a bath, dressing, combing hair, or using the toilet), whereas others reported their problematic ADLs more generically (eg, problems with bathroom activities). Therefore, specific self-care ADLs like showering may perhaps even be underestimated.

\section{Occupational Therapy}

COPD patients entering pulmonary rehabilitation experience clear difficulties with a variety of ADLs, which cannot be explained confidently by clinical determinants. Therefore, an intake by an occupational therapist, including a semistructured interview, like 


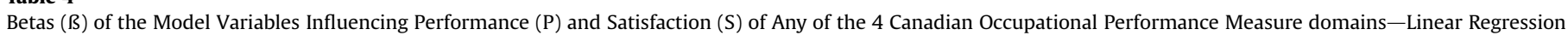

\begin{tabular}{|c|c|c|c|c|c|c|c|c|}
\hline & \multicolumn{2}{|c|}{ Self-care $ß$} & \multicolumn{2}{|c|}{ Productivity ß } & \multicolumn{2}{|l|}{ Leisure $ß$} & \multicolumn{2}{|c|}{ Mobility ß } \\
\hline & $\mathrm{P}$ & $S$ & $\mathrm{P}$ & $\mathrm{S}$ & $\mathrm{P}$ & $\mathrm{S}$ & $\mathrm{P}$ & $\mathrm{S}$ \\
\hline Age & & & & 0.026 & & & & 0.037 \\
\hline (years) 95\% CI: L & & & & 0.007 & & & & 0.021 \\
\hline $\mathrm{U}$ & & & & 0.045 & & & & 0.052 \\
\hline Sex & & -0.532 & & & & -0.782 & & \\
\hline $1=m, 2=w 95 \% \mathrm{CI}: \mathrm{L}$ & & -0.927 & & & & -1.216 & & \\
\hline $\mathrm{U}$ & & -0.138 & & & & -0.347 & & \\
\hline 6MWD & 0.009 & 0.014 & & & 0.016 & 0.017 & 0.010 & \\
\hline (\%pred) 95\% CI: L & 0.001 & 0.003 & & & 0.006 & 0.006 & 0.003 & \\
\hline $\mathrm{U}$ & 0.016 & 0.025 & & & 0.026 & 0.028 & 0.016 & \\
\hline FMI & & -0.063 & & & & & & \\
\hline$(\mathrm{kg} / \mathrm{m} 2)$ 95\% CI: L & & -0.119 & & & & & & \\
\hline $\mathrm{U}$ & & -0.007 & & & & & & \\
\hline LTOT & & & -0.522 & & & & & \\
\hline$(1=$ no, $2=$ yes) $95 \% \mathrm{CI}: \mathrm{L}$ & & & -0.925 & & & & & \\
\hline $\mathrm{U}$ & & & -0.120 & & & & & \\
\hline Walking aid & & 0.504 & & & & & & \\
\hline ( $1=$ no, $2=$ yes) $95 \% \mathrm{CI}: \mathrm{L}$ & & 0.038 & & & & & & \\
\hline $\mathrm{U}$ & & 0.970 & & & & & & \\
\hline MRC & & & -0.192 & -0.259 & & & -0.281 & -0.385 \\
\hline (grade) 95\% CI: L & & & -0.362 & -0.451 & & & -0.411 & -0.514 \\
\hline $\mathrm{U}$ & & & -0.023 & -0.067 & & & -0.150 & -0.256 \\
\hline SGRQ $_{\text {Total }}$ & -0.024 & -0.024 & $-\mathbf{0 . 0 2 7}$ & -0.027 & -0.028 & -0.019 & & \\
\hline (points) 95\% CI: L & -0.035 & -0.041 & -0.040 & -0.041 & -0.042 & -0.034 & & \\
\hline $\mathrm{U}$ & -0.013 & -0.008 & -0.014 & -0.013 & -0.014 & -0.003 & & \\
\hline Anxiety & & & & & -0.079 & & & \\
\hline (points) 95\% CI: L & & & & & -0.126 & & & \\
\hline $\mathrm{U}$ & & & & & -0.032 & & & \\
\hline Depression & & -0.058 & & & & $-\mathbf{0 . 0 7 7}$ & -0.039 & -0.059 \\
\hline (points) 95\% CI: L & & -0.113 & & & & -0.133 & -0.070 & -0.096 \\
\hline $\mathrm{U}$ & & -0.003 & & & & -0.020 & -0.007 & -0.022 \\
\hline Model $\mathrm{R}^{2}$ & 0.076 & 0.098 & 0.124 & 0.104 & 0.183 & 0.147 & 0.102 & 0.103 \\
\hline
\end{tabular}

ßs represent an average increase in the scores per unit increase in the independent variable. No statistical significance was detected for Living status, FEV ${ }_{1}$, and FFMI.

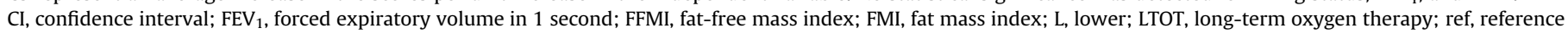
value; m, men; SGRQ, St. George's Respiratory Questionnaire; U, upper; w, women; 6MWD, 6-minute walk distance.

the COPM, seems necessary to develop a patient-tailored pulmonary rehabilitation program. Moreover, the current data clearly provide a rationale to assess the additional effects of occupational therapy on the functional performance of patients with COPD as part of a comprehensive pulmonary rehabilitation program. Indeed, energy conservation techniques in COPD patients during ADL reduces energy cost and dyspnea perception. ${ }^{35}$ Reduced energy cost and dyspnea perception during ADLs may well increase performance and satisfaction scores of problematic ADLs. This warrants future randomized controlled trials.

To conclude, COPD patients have an enormous variety of problematic ADLs. Clinical determinants are weakly associated with problematic ADLs, which emphasize the need for assessing problematic ADLs within the individual patient so as to plan tailored interventions.

\section{Acknowledgments}

Paul Willems of Human Movement Science, NUTRIM School for Nutrition, Toxicology and Metabolism, and Suzanne Goossens, Mieke Kersten, Michelle van Mook and Malou Lammers of the Department of Occupational Therapy, Zuyd University, Heerlen, Netherlands, are gratefully acknowledged for their help with electronic data processing.

\section{Supplementary data}

Supplementary data associated with this article can be found, in the online version, at doi:10.1016/j.jamda.2011.01.002

\section{References}

1. Young Y, Boyd CM, Guralnik JM, et al. Does self-reported function correspond to objective measures of functional impairment? J Am Med Dir Assoc 2010;11: 645-653.

2. Nici L, Donner C, Wouters E, et al. American Thoracic Society/European Respiratory Society statement on pulmonary rehabilitation. Am J Respir Crit Care Med 2006;173:1390-1413.

3. Stull DE, Leidy NK, Jones PW, et al. Measuring functional performance in patients with COPD: A discussion of patient-reported outcome measures. Curr Med Res Opin 2007;23:2655-2665.

4. Williams V, Bruton A, Ellis-Hill C, et al. What really matters to patients living with chronic obstructive pulmonary disease? An exploratory study. Chron Respir Dis 2007;4:77-85.

5. Leidy NK, Haase JE. Functional performance in people with chronic obstructive pulmonary disease: A qualitative analysis. ANS Adv Nurs Sci 1996;18:77-89.

6. Law M, Baptiste S, Carswell A, et al. Canadian Occupational Performance Measure. Toronto: CAOT Publications ACE; 1998.

7. Sewell L, Singh SJ. The Canadian Occupational Performance Measure: Is it a reliable measure in clients with chronic obstructive pulmonary disease? $\mathrm{Br} \mathrm{J}$ Occup Ther 2001;64:1194-1200.

8. Dedding C, Cardol M, Eyssen IC, et al. Validity of the Canadian Occupational Performance Measure: A client-centred outcome measurement. Clin Rehabil 2004;18:660-667.

9. Spruit MA, Vanderhoven-Augustin I, Janssen PP, et al. Integration of pulmonary rehabilitation in COPD. Lancet 2008;371:12-13.

10. Sewell L, Singh SJ, Williams JE, et al. Can individualized rehabilitation improve functional independence in elderly patients with COPD? Chest 2005;128: 1194-1200.

11. World Health Organization. International Classification of Functioning, Disability and Health: ICF. Geneva: World Health Organization; 2001.

12. Skumlien S, Haave E, Morland L, et al. Gender differences in the performance of activities of daily living among patients with chronic obstructive pulmonary disease. Chron Respir Dis 2006;3:141-148.

13. Crockett AJ, Cranston JM, Moss JR, et al. The impact of anxiety, depression and living alone in chronic obstructive pulmonary disease. Qual Life Res 2002;11: 309-316.

14. Katz PP, Eisner MD, Yelin EH, et al. Functioning and psychological status among individuals with COPD. Qual Life Res 2005;14:1835-1843. 
15. Tsukino M, Nishimura K, Ikeda A, et al. Physiologic factors that determine the health-related quality of life in patients with COPD. Chest 1996;110:896-903.

16. Katz PP, Gregorich S, Eisner M, et al. Disability in valued life activities among individuals with COPD and other respiratory conditions. J Cardiopulm Rehabil Prev 2010;30:126-136.

17. Okubadejo AA, O'Shea L, Jones PW, et al. Home assessment of activities of daily living in patients with severe chronic obstructive pulmonary disease on longterm oxygen therapy. Eur Respir J 1997;10:1572-1575.

18. Garrod R, Bestall JC, Paul EA, et al. Development and validation of a standardized measure of activity of daily living in patients with severe COPD: The London Chest Activity of Daily Living scale (LCADL). Respir Med 2000;94:589-596.

19. Probst VS, Troosters T, Coosemans I, et al. Mechanisms of improvement in exercise capacity using a rollator in patients with COPD. Chest 2004;126:1102-1107.

20. Mostert R, Goris A, Weling-Scheepers C, et al. Tissue depletion and health related quality of life in patients with chronic obstructive pulmonary disease. Respir Med 2000;94:859-867.

21. den Hoed M, Westerterp KR. Body composition is associated with physical activity in daily life as measured using a triaxial accelerometer in both men and women. Int J Obes (Lond) 2008;32:1264-1270.

22. Rodriguez Gonzalez-Moro JM, de Lucas Ramos P, Izquierdo Alonso JL, et al. Impact of COPD severity on physical disability and daily living activities: EDIPEPOC I and EDIP-EPOC II studies. Int J Clin Pract 2009;63:742-750.

23. Jones PW. Activity limitation and quality of life in COPD. COPD 2007;4: 273-278.

24. ATS statement: Guidelines for the six-minute walk test. Am J Respir Crit Care Med 2002;166:111-117.

25. Troosters T, Gosselink R, Decramer M. Six minute walking distance in healthy elderly subjects. Eur Respir J 1999;14:270-274.
26. Spruit MA, Wouters EF. New modalities of pulmonary rehabilitation in patients with chronic obstructive pulmonary disease. Sports Med 2007;37:501-518.

27. Steiner MC, Barton RL, Singh SJ, et al. Bedside methods versus dual energy X ray absorptiometry for body composition measurement in COPD. Eur Respir J 2002;19:626-631.

28. Spruit MA, Pennings HJ, Janssen PP, et al. Extra-pulmonary features in COPD patients entering rehabilitation after stratification for MRC dyspnea grade. Respir Med 2007;101:2454-2463.

29. Lexell EM, Iwarsson S, Lexell J. The complexity of daily occupations in multiple sclerosis. Scand J Occup Ther 2006;13:241-248.

30. Kjeken I, Slatkowsky-Christensen B, Kvien TK, et al. Norwegian version of the Canadian Occupational Performance Measure in patients with hand osteoarthritis: Validity, responsiveness, and feasibility. Arthritis Rheum 2004;51: 709-715.

31. Law M, Baptiste S, McColl M, et al. The Canadian Occupational Performance Measure: An outcome measure for occupational therapy. Can J Occup Ther 1990;57:82-87.

32. Lacasse Y, Brosseau L, Milne S, et al. Pulmonary rehabilitation for chronic obstructive pulmonary disease. Cochrane Database Syst Rev 2002;(3). CD003793.

33. Nicolson P, Anderson P. Quality of life, distress and self-esteem: A focus group study of people with chronic bronchitis. Br J Health Psychol 2003;8:251-270.

34. Singh S. Out-Patient Pulmonary Rehabilitation. Pisa, ERS congress. Available at http://www.ers-education.org/pages/default.aspx?id=335; 2008. Accessed February 2010.

35. Velloso M, Jardim JR. Study of energy expenditure during activities of daily living using and not using body position recommended by energy conservation techniques in patients with COPD. Chest 2006;130:126-132. 